\title{
PULMONARY VALVE ENDOCARDITIS
}

\section{WITH SEPTIC PULMONARY THROMBOEMBOLISM} IN A PATIENT WITH VENTRICULAR SEPTAL DEFECT

\author{
HYO EUN PARK, MD ${ }^{1,2}$, GOO-YEONG CHO, MD, PHD ${ }^{1}$, HYUNG-KWAN KIM, MD, PHD², \\ YONG-JIN KIM, MD, PHD² AND DAE-WON SOHN, MD, PHD \\ ${ }^{1}$ DIVISION OF CARDIOLOGY, DEPARTMENT OF INTERNAL MEDICINE, SEOUL NATIONAL UNIVERSITY COLLEGE OF MEDICINE, \\ CARDIOVASCULAR CENTER, SEOUL NATIONAL UNIVERSITY BUNDANG HOSPITAL, SEONGNAM, KOREA \\ ${ }^{2}$ DIVISION OF CARDIOLOGY, DEPARTMENT OF INTERNAL MEDICINE, SEOUL NATIONAL UNIVERSITY COLLEGE OF MEDICINE, \\ SEOUL NATIONAL UNIVERSITY HOSPITAL, SEOUL, KOREA
}

We describe a 42-year-old man who presented as life-threatening sepsis and septic shock with multiple septic pulmonary embolism and septic pneumonia due to pulmonary valve endocarditis. The patient had history of untreated ventricular septal defect (VSD) and complained of severe dyspnea and orthopnea. Transthoracic and transesophageal echocardiograms revealed severe pulmonary regurgitation with large, hypermobile vegetation on pulmonary valve and right ventricular outflow tract (RVOT), and a small subarterial type VSD. Emergency operation was done due to rapid deterioration of the patient, and after 6 weeks of antibiotics coverage, he was discharged.

KEY WORDS: Pulmonary valve - Endocarditis - Ventricular septal defect.

\section{INTRODUCTION}

The incidence of community-acquired native-valve endocarditis has been reported as 1.7 to 6.2 cases per 100,000 person-years, ${ }^{122}$ of which right sided endocarditis comprises only $5-10 \%$. Right sided endocarditis is more common in patients with predisposing conditions such as drug abuse, indwelling catheters, pacemaker leads $s^{3)}$ or structural heart disease. Most of the cases involve tricuspid valve which makes pulmonary valve endocarditis without involvement of tricuspid valve even rarer disease, and previously fewer than 90 cases of pulmonary valve endocarditis have been reported. ${ }^{45)}$ Although there have been case reports of pulmonary valve endocarditis previously, they usually presented as septic pulmonary embolism with mild pulmonary regurgitation, ${ }^{5-7)}$ and as to our knowledge, there has not been a report of a patient who presented with fulminant pulmonary valve endocarditis as in our patient.

Here we describe a rare case of a patient with history of untreated ventricular septal defect (VSD) who presented as life-threatening sepsis and septic embolism due to pulmonary valve endocarditis.

\section{CASE}

A 42-year-old man visited emergency department (ED) with dyspnea. He had heard of a VSD 20 years ago, but had refused to visit hospital for further evaluation afterwards. He had an untreated panic disorder, which kept him at home for 7-8 years. He had intermittent fever and chill for a few months and lost 20 kilograms of body weight. He intermittently applied moxa to abdomen and irregularly visited a primary physician and was subscribed with oral antibiotics under impression of pneumonia. On the day of ED visit, he went to the primary physician due to New York Heart Association Functional class III dyspnea, and was referred to our hospital for further evaluation. The initial lab showed leukocytosis, anemia and thrombocytopenia with increased Creactive protein, and increased NT-proBNP level which was $13,342 \mathrm{pg} / \mathrm{mL}$. Oxygen was applied via facial mask at 15

Received: October 19, 2009 •Revised: November 30, 2009 • Accepted: November 30, 2009

Address for Correspondence: Goo-Yeong Cho, Division of Cardiology, Department of Internal Medicine, Seoul National University College of Medicine,

Cardiovascular Center, Seoul National University Bundang Hospital, 166 Gumi-ro, Bundang-gu, Seongnam 463-707, Korea

Tel: +82-31-787-7024, Fax: +82-31-787-4051, E-mail: cardioch@medimail.co.kr 
$\mathrm{L} / \mathrm{min}$, at which oxygen saturation $\left(\mathrm{SaO}_{2}\right)$ was $91 \%$. The initial chest X-ray showed multifocal consolidation and grassground opacity (GGO) at both lung fields. Transthroacic echocardiogram revealed dilated right ventricle (RV) with hypertrophy and severe pulmonary regurgitation with large, hypermobile vegetation on pulmonary valve and right ventricular outflow tract (RVOT). The pulmonary valve was severely destructed, with almost invisible remnant functioning leaflet tissue, which accounted for the torrential pulmonary regurgitation (Fig. 1A). Other cardiac valves were clear, with normal morphology and function. Chest CT showed diffuse irregular thickening of pulmonary valve, multifocal pulmonary embolism and diffuse GGO with multifocal patchy and nodular consolidations at both lungs (Fig. 2). The clinical course of the patient progressed rapidly, with development of hypotension and rapid progression of hypoxia despite full oxygen and inotropics supplement. The patient monitor revealed $\mathrm{SaO} 2$ of $50 \%$ even at full oxygen support via facial mask and systolic blood pressure of $77 \mathrm{mmHg}$, and he was admitted to intensive care unit (ICU) after intubation. A portable transesophageal echocardiogram revealed a small ventricular septal defect with left to right shunt and multiple huge mobile echogenic mass at right ventricle side of VSD and RVOT (Fig. 1B). The patient was sent for emergency operation. A $0.8 \mathrm{~cm}$-sized subarterial type VSD was repaired. Massive amount of vegetation and thrombus was found in RV and RVOT which extended to pulmonary valve and caused extensive valve destruction. The pulmonary valve was replaced with a mechanical valve. No bacteria was grown from the blood culture, but pathologic specimen of the tissue showed fibrinous exudates with colonies of numerous cocci and chronic active inflammation. A combination of ampicillin, nafcillin and gentamicin was continued, and at post-op day 5, the patient was transferred to sub-ICU. After 6 weeks of combination antibiotics therapy, the patient was discharged.
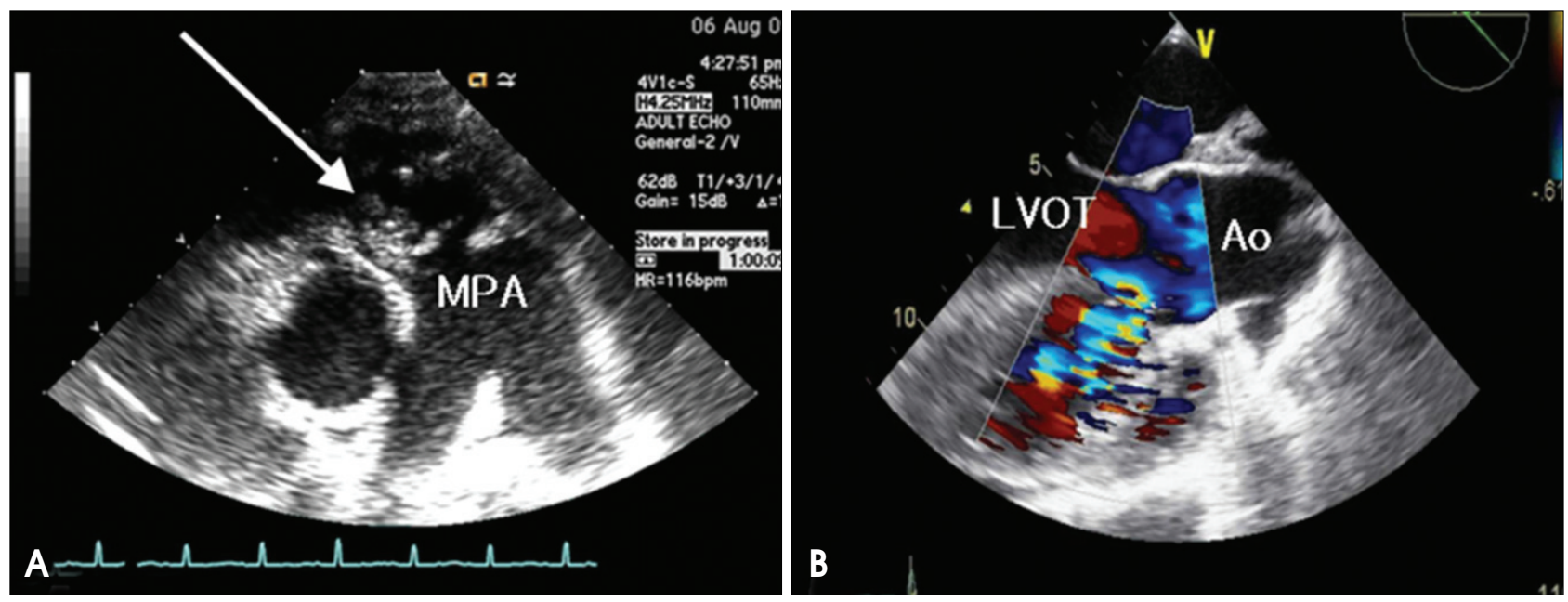

Fig. 1. A: Transthoracic parasternal short axis view showing large, mobile vegetation (white arrow) on pulmonary valve. B: Transesophageal echocardiography showing a small subarterial type VSD with left to right shunt. Large amount of thrombus and vegetation were found in right ventricle. MPA: main pulmonary artery, LVOT: left ventricular outflow tract, Ao: aorta.
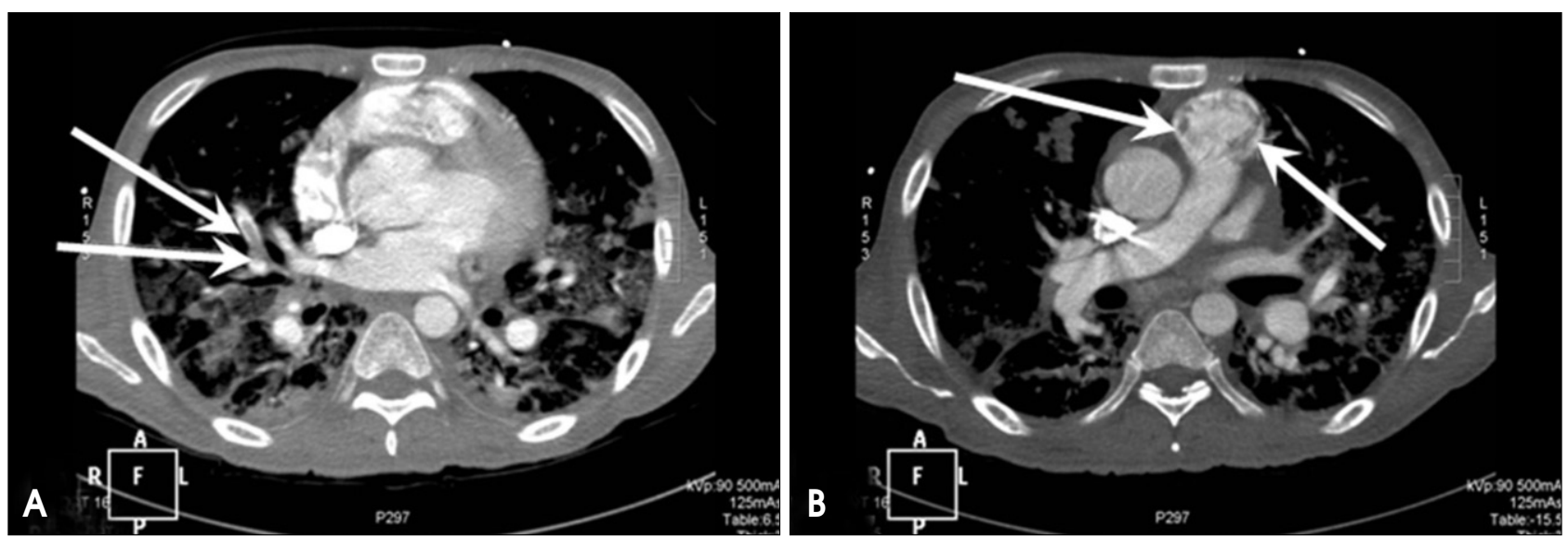

Fig. 2. Initial chest CT showing (A) pulmonary embolism (white arrows) and (B) destructed pulmonary valve (white arrows). Lung parenchyme on CT shows diffuse grass ground opacity with multifocal patchy and nodular consolidations at both lungs suggesting combined septic pneumonia. 


\section{DISCUSSION}

Right-sided endocarditis is relatively rare and mainly affects the tricuspid valve. Pulmonary valve endocarditis is even rarer than tricuspid valve endocarditis, and comprises less than $2 \%$ of hospital admissions for endocarditis. Different hemodynamic pressure gradients across the valves, different frequencies of underlying congenital or acquired valvular abnormalities and lower blood oxygen content in right chambers may all contribute to the lower incidence of right sided endocarditis, especially involving pulmonary valves. ${ }^{58)}$ Majority of isolated pulmonary valve endocarditis occurs in patients with congenital heart disease, ${ }^{7 / 9)(10)}$ as in our case. In this case, isolated pulmonary valve endocarditis may have been initiated by the jet or turbulent flow created by VSD, which then spread to pulmonary valves.

Right sided endocarditis differs in several aspects from left sided endocarditis. Isolated right sided endocarditis without left sided involvement is generally regarded to have a relatively benign prognosis with low in-hospital mortality, and the primary approach recommended is conservative management with antibiotics with surgery being necessary in only a small population. Musci et al.11) have reported that patients with left sided involvement not only show poorer clinical outcome than those with isolated right sided endocarditis, but also present more with septic shock and renal insufficiency, and were more likely to undergo emergency operation due to worsening conditions.

Due to much common involvement of endocarditis on left-sided cardiac valves, much less is clear about the indications for surgery and its timing in patients with right-sided endocarditis. The key elements for determining the timing of surgery in right-sided infective endocarditis are type of infecting organism (especially Staphylococcus aureus and Gram-negative bacilli), secondary heart failure, severe valvular dysfunction, response to appropriate antibiotic therapy, presence and extent of local invasion, pulmonary involvement such as septic emboli or cavitation, and systemic involvement such as disseminated intravascular coagulopathy or acute renal failure. ${ }^{12)}$ However, no definite guideline is present to aid in decision making, and attending team's experience and each patient's clinical status are important in decision-making. The complexity of infective endocarditis and variable clinical presentation make it difficult to present a standardized treatment guideline, which necessitates an individualized and patient-tailored approach.

Pulmonary valve endocarditis, even in the presence of structural heart disease, is rare and is difficult to diagnose without suspicion, since the first clinical manifestations often mimic pulmonary infection caused by septic pulmonary embolism. This delays appropriate treatment, and thus careful examination and history taking of responsible physician are very important. Also, thorough echocardiographic evaluation of the all cardiac valves, including right sided valves, should be carried out in all patients with suspected infective endocarditis, especially when the patient has a risk factor.

\section{REFERENCES}

1. Berlin JA, Abrutyn E, Strom BL, Kinman JL, Levison ME, Korzeniowski OM, Feldman RS, Kaye D. Incidence of infective endocarditis in the Delaware Valley, 1988-1990. Am J Cardiol 1995;76:933-6.

2. Hogevik H, Olaison L, Andersson R, Lindberg J, Alestig K. Epidemiologic aspects of infective endocarditis in an urban population. A 5-year prospective study. Medicine (Baltimore) 1995;74:324-39.

3. Ha JK, Kim SH, Kim SH, An BJ, Chun KJ, Hong TJ, Shin YW, Chung SW, Kim JW. Infected endocarditis related pacemaker leads: a case report. J Korean Soc Echocardiogr 2001;9:70-4.

4. Tariq M, Smego RA Jr, Soofi A, Islam N. Pulmonic valve endocarditis. South Med J 2003;96:621-3.

5. Nishida K, Fukuyama O, Nakamura DS. Pulmonary valve endocar-ditis caused by right ventricular outflow obstruction in association with sinus of valsalva aneurysm: a case report. J Cardiothorac Surg 2008;3:46.

6. Moyssakis I, Kazazis A, Lionakis N, Vlahodimitris I, Petrikos G, Votteas V. Late recurrence of pulmonic valve endocarditis in an adult patient with ventricular septal defect: a case report. J Heart Valve Dis 2009;18:167-9.

7. Nakauchi Y, Taniguchi M, Miyamura Y, Ishise T, Miyazaki S. [Pulmonary septic embolism with right side infectious endocarditis and ventricular septal defect: a case report.] J Cardiol 2007;50:383-7.

8. Ali AA, Halstead JC, Hosseinpour AR, Ali ZA, Kumar S, Wallwork J. Replacement of a regurgitant pulmonary valve with a stentless bioprosthesis. Ann Thorac Surg 2004; 78:1467-8.

9. Ramadan FB, Beanlands DS, Burwash IG. Isolated pulmonic valve endocarditis in healthy hearts: a case report and review of the literature. Can J Cardiol 2000;16:1282-8.

10. Kim SH, Woo HY, Ha JH, Kim WC, Choi YS, Rhee DH, Kim JH, Park CS, Oh YS, Youn HJ, Chung WS, Hong SJ. A case of patent ductus arteriosus associated with pulmonary valve endocarditis. J Cardiovasc Ultrasound 2006; 14:33-5.

11. Musci M, Siniawski H, Pasic M, Grauhan O, Weng Y, Meyer R, Yankah CA, Hetzer R. Surgical treatment of right-sided active infective endocarditis with or without involvement of the left heart: 20-year single center experience. Eur J Cardiothorac Surg 2007;32:118-25.

12. Melina G, El-Hamamsy I, Sinatra R, Yacoub MH. Late fulminant pulmonary valve endocarditis after the Ross operation. J Thorac Cardiovasc Surg Inpress 2009. 